1 Universidade Federal de Minas Gerais (UFMG)

- Belo Horizonte (MG), Brasil.

danisantosicm@gmail.com

${ }^{2}$ Universidade Federal de Minas Gerais (UFMG)

- Belo Horizonte (MG),

Brasil. Secretaria Municipal de Saúde de Belo

Horizonte (SMSA-PBH),

Núcleo de Vigilância em

Saúde Ambiental - Belo

Horizonte (MG), Brasil.

danielaochoac@pbh.gov.br

3 Universidade Federal de Minas Gerais (UFMG)

- Belo Horizonte (MG),

Brasil.

mvpolignano@gmail.com

${ }^{4}$ Universidade Federal de

Minas Gerais (UFMG)

- Belo Horizonte (MG),

Brasil.

lenicevillela@gmail.com

5 Universidade Federal de

Minas Gerais (UFMG)

- Belo Horizonte (MG)

Brasil.

vanessaalmeidaufmg@

gmail.com

\section{Revitalização da Bacia do Ribeirão do Izidora: educação ambiental como estratégia}

\author{
Revitalization of the Ribeirão do Izidora Basin: environmental \\ education as a strategy
}

Daniela Santos Serpa Siqueira', Daniela de Almeida Ochoa Cruz², Marcos Vinícius Polignano ${ }^{\mathbf{3}}$ Lenice de Castro Mendes Villela $\mathbf{4}^{4}$ Vanessa de Almeida Guerra ${ }^{\mathbf{5}}$

RESUMO Com a crescente urbanização e aumento da população, a fauna e a flora têm sido amplamente devastadas. Este artigo consiste em estudo descritivo, na forma relato de experiência, de um projeto de extensão da Universidade Federal de Minas Gerais (UFMG) sobre a revitalização da Bacia do Ribeirão do Izidora em Belo Horizonte. Ações intersetoriais de gestão e educação ambiental são realizadas na área de um centro de saúde e em doze escolas municipais que visam contribuir para promoção da saúde e melhoria da qualidade de vida da população assistida, dentro de uma abordagem ecossistêmica de saúde. Espera-se ampliar para outras bacias do município e fomentar a construção de planos municipais de Gerenciamento de Resíduos Sólidos Urbanos.

PALAVRAS-CHAVE Educação ambiental. Bacia hidrográfica. Promoção da saúde.

ABSTRACT The increase in urbanization and population, fauna and flora have been largely devastated. This article consists in a descriptive study, in the form of experience reports, of the actions developed in an UFMG (Federal University of Minas Gerais) extension project on the revitalization of the Ribeirão do Izidora Basin, in Belo Horizonte. Intersectoral actions of management and environmental education are developed and implemented in one health center and twelve municipal schools with the objective to contribute to health promotion and improvements of life quality to the assisted population, within an ecosystemic health approach. It is expected to expand to other municipal basins and encourage the construction of municipal plans of Solid Waste Management.

KEYWORDS Environmental education. Hydrographic basins. Promotion health. 


\section{Introdução}

Todos os ambientes da vida cotidiana, tais como o trabalho, lazer, espaço doméstico, entre outros, podem contribuir para determinar a saúde dos sujeitos à medida em que apresentem fatores que auxiliem em uma melhor qualidade de vida. Estes fatores e mecanismos sociais, econômicos, culturais, étnicos/raciais, psicológicos e comportamentais, que se relacionam de modo particular, são denominados Determinantes Sociais de Saúde (DSS) (BUSS; PELLEGRINI FILHO, 2007).

Um modo de impactar os DSS é a inserção de práticas de promoção da saúde, que se constituem de estratégias, que visam o fortalecimento da capacidade individual e coletiva de reduzir vulnerabilidades, por meio do empoderamento dos sujeitos e pelo desenvolvimento de habilidades, conhecimentos e atitudes favoráveis à saúde. A adoção de uma concepção ampliada de saúde incentiva o protagonismo dos indivíduos na construção de saúde e evidencia a responsabilidade do Estado na construção de condições de vida adequadas às necessidades da população (SILVA; BAPTISTA, 2015).

De modo transversal, extrapolando o setor saúde, medidas que visam aumentar a saúde, bem-estar e que não se dirigem a doenças específicas são medidas conquistadas por meio de ações intersetoriais e interdisciplinares (SILVA ET AL., 2014).

A educação em saúde possui caráter abrangente, sendo considerada um dos principais dispositivos para a viabilização da promoção da saúde, auxiliando no desenvolvimento da responsabilidade individual, na prevenção de doenças, na desconstrução de práticas recorrentes prejudiciais à saúde, entre outros (JANINI; BESSLER; VARGAS, 2015).

Destacam-se as ações de educação ambiental, fundamentais para estimular a consciência da comunidade (NEVES; LIBEL; FREITAS, 2016). Oliveira et al. (2015), que consideram a educação ambiental como um movimento a favor de um maior reconhecimento e mobilização da questão socioambiental. No que diz respeito às questões ambientais e sua relação com a saúde, há uma preocupação mundial acerca da urbanização crescente, que gradativamente intensificou a poluição causada, principalmente, por resíduos descartados de modo incorreto e que impactam os recursos hídricos, como as bacias hidrográficas, desafiando a implantação de ações para o desenvolvimento sustentável nos centros urbanos e para melhoria da qualidade de vida das populações (GOUVEIA, 1999).

As bacias hidrográficas são caracterizadas por áreas geograficamente delimitadas que drenam as suas águas para um mesmo curso d'água, que possui solo, fauna e flora essenciais para manter a sua vitalidade, onde, por vezes, estão inseridas atividades antrópicas que as impactam.

A Bacia do Ribeirão do Izidora está localizada na porção Norte de Belo Horizonte e tem área de abrangência nas regionais Venda Nova, Norte e Pampulha, passando por 69 bairros. O principal curso d'água da bacia é o Ribeirão do Izidora, que é afluente do Ribeirão do Onça, pertencente à Bacia do Rio das Velhas e, consequentemente, à do Rio São Francisco.

Na percepção do contexto de graves problemas ambientais que Belo Horizonte enfrenta, como lançamentos de esgoto in natura nos cursos de água, seja doméstico ou industrial, ocupação intensa e desordenada de encostas e fundos de vale, destinação incorreta dos resíduos nas áreas de suas sub-bacias, em especial, as do Ribeirão do Izidora.

Diante desse quadro, foram discutidas e formuladas propostas de revitalização da Bacia Hidrográfica do Izidora, por meio de seu Núcleo de Revitalização, criado após a homologação da Resolução $\mathrm{n}^{0}$ 318/2012 no Conselho Municipal de Saúde de Belo Horizonte vinculado à Secretaria Municipal de Saúde, a partir do qual se gerou o Plano de Ações do Núcleo com dez grandes ações. Para cumprir a ação Gerenciamento de Resíduos Sólidos Urbanos, criou-se o Projeto Izidora (CRUZ ET AL., 2014). 
Trata-se de um projeto de interface com o Núcleo de Revitalização da Bacia do Ribeirão do Izidora e, também, de extensão da Universidade Federal de Minas Gerais (UFMG) intitulado 'Transformação da Realidade Ambiental para Promover a Saúde no Território'. O Projeto Izidora foi premiado no XIX Encontro de Extensão da UFMG, em outubro de 2016. A UFMG, por meio do curso Gestão de Serviços de Saúde, destacou-se por esse projeto de extensão em interface com pesquisa. Segundo Santos (2005), a extensão, na Universidade envolve uma vasta área de prestação de serviços para públicos variados, remetendo a ações de responsabilidade social, conferindo-lhe participação ativa na construção da coesão social na luta contra a degradação ambiental.

Nessa perspectiva, ressalta-se que o Projeto Izidora, para promover a gestão e educação ambiental no que concerne à implantação do Gerenciamento de Resíduos Sólidos Urbanos, tem desenvolvido ações que abordam o uso consciente de recursos naturais e boas práticas pautadas na sustentabilidade, visando à transformação ambiental do território da Bacia do Izidora, à construção de um processo de gestão e educação ambiental de caráter participativo e permanente e, consequentemente, à melhoria da qualidade de vida e promoção da saúde da população na área.

Para isso, o projeto tem buscado identificar e fortalecer parcerias com as Escolas Municipais e Centros de Saúde que fazem parte da área de abrangência da Bacia e, assim, promover a participação e o empoderamento de alunos, comunidade, profissionais de saúde e educação da prefeitura de Belo Horizonte.

Este artigo foi estruturado em três etapas: Guardiões da Saúde, que relata a experiência vivida no Centro de Saúde Etelvina Carneiro; Guardiões da Escola, a qual descreve as ações desenvolvidas nas escolas participantes do Projeto, e, por fim, uma reflexão dos resultados alcançados, até o momento, e quais são os resultados esperados.

\section{Material e métodos}

Para o desenvolvimento deste estudo, utilizou-se a metodologia participativa como ferramenta que implica coparticipação de diferentes atores sociais envolvidos no processo, na perspectiva de conhecerem o contexto no qual se encontram inseridos e as situações que necessitam de intervenção no sentido de buscarem as alternativas para superação. Trata-se, portanto, de um processo de reflexão e ação com a participação ativa dos sujeitos envolvidos, com ênfase na valorização do saber local que interage com o saber científico.

O cenário do estudo refere-se ao território e área adstrita do Centro de Saúde Etelvina Carneiro e das Escolas Municipais da Regional Venda Nova, Norte e Pampulha do município de Belo Horizonte/Minas Gerais. Ressalta-se que o território em que a Bacia está inserida apresenta Índice de Vulnerabilidade Social (IVS) médio, elevado e muito elevado.

A partir da metodologia proposta, foi possível direcionar o desenvolvimento das atividades que ocorreu em duas etapas, norteadas por meio dos planos de ação. Inicialmente, criada por profissionais da indústria japonesa, o plano de ação é uma ferramenta de gestão que permite planejar atividades pré- estabelecidas, funcionando como um mapeamento das atividades, de fácil compreensão e visualização (VEIGA ET AL., 2013). Apesar de desenvolvido na indústria, a ferramenta pode ser adaptada para demais áreas, conforme necessidade, por isso utilizaram-se os planos de ação do Centro de Saúde e das Escolas como instrumento de gestão, que permite controlar e acompanhar o andamento das ações desenvolvidas e seus resultados.

Para o desenvolvimento do projeto, utilizou-se de duas etapas descritas a seguir. A primeira denominada Guardiões da Saúde, representada pelos Agentes Comunitários de Saúde (ACS) e Agentes de Combate a Endemias (ACE). Nessa etapa, no Centro 
de Saúde (CS), foram desenvolvidas as seguintes atividades: sensibilização da equipe; visita à área de abrangência para a realização do diagnóstico ambiental e identificação de pontos mais vulneráveis; capacitação dos 'Guardiões da Saúde'; coleta de dados realizada pelos Guardiões e elaboração do Plano de Ação a partir dos problemas identificados.

Na segunda etapa denominada Guardiões da Escola, representada pela comunidade escolar, houve intensificação das ações de gestão e educação ambiental, no âmbito da escola e do seu entorno contemplando as seguintes ações: sensibilização, capacitação, visita à bacia hidrográfica, coleta de dados, elaboração do plano de ações, organização de um seminário para apresentação do projeto e das propostas preliminares dos planos de ações. As escolas municipais receberam o apoio da Coordenação e técnicos do Programa Saúde na Escola (PSE), de técnicos e gestores das Secretarias de Meio Ambiente e Saúde proporcionando o desenvolvimento das etapas na comunidade escolar. Foi apresentada a realidade do município em relação ao tratamento dos resíduos sólidos. Aplicouse lista de verificação da realidade da escola, como instrumento de diagnóstico dos resíduos, consumo de água e energia elétrica, para que fosse preenchida pelos alunos envolvidos. Em seguida, realizou-se coleta de dados utilizando a lista de verificação para a realização do diagnóstico de cada escola e visita a diversos pontos da Bacia do Ribeirão Izidora. Diante dos problemas apresentados, elaborou-se proposta de plano de ação para gerenciamento ambiental no âmbito da escola, principalmente, e do seu entorno, buscando melhorias em todos os aspectos.

\section{Resultados e discussão}

Ao pensar que saúde é produzida no cotidiano dos indivíduos e que a Promoção da Saúde extrapola a atuação do setor Saúde e direciona suas ações para grupos sociais e com responsabilidade do Estado, para o desenvolvimentos dessas ações, o Projeto Izidora conta com parcerias firmadas entre representantes da Secretaria Municipal de Saúde, do Conselho Municipal de Saúde, Distrital e Local, da Superintendência de Limpeza Urbana, Secretaria Municipal do Meio Ambiente, Secretaria Municipal de Educação, Projeto Manuelzão/UFMG, entre outros colaboradores da cidade de Belo Horizonte, representantes que possibilitam a força para desenvolvimento de ações estratégicas e que podem gerar mudanças na realidade social e melhoria na qualidade de vida da população.

Inicialmente, as ações referentes ao Projeto desenvolveram-se na área de abrangência do Centro de Saúde Etelvina Carneiro, cuja escolha advém de uma proposta do Núcleo de Revitalização da Bacia do Ribeirão do Izidora, de uma demanda específica da gerência local, com base em fatores que impactam diretamente a saúde do indivíduo, como o alto índice de circulação do vírus da dengue. Ressalta-se que o território em que a Bacia está inserida apresenta IVS médio, elevado e muito elevado.

No projeto de extensão, ações com docentes, discentes, profissionais de saúde e comunidade possibilitaram o desenvolvimento de frentes de trabalho motivadas para desenvolverem suas ações em todo o território. Atualmente, além do trabalho no Centro de Saúde Etelvina Carneiro com os denominados 'Guardiões da Saúde', desenvolveu-se, em parceria, o trabalho de educação ambiental nas escolas municipais da região da Bacia com os 'Guardiões da Escola'. Essas ações, juntamente com as equipes envolvidas, buscam o desenvolvimento das ações propostas para a revitalização da Bacia do Ribeirão do Izidora.

\section{Guardiões da Saúde}

Para dar início à implantação do Projeto, foram realizados encontros e capacitações com os profissionais de saúde, da educação e lideranças comunitárias sobre a temática 
bacia hidrográfica, resíduos sólidos e educação ambiental. A orientação dos serviços de saúde, bem como a mobilização e a capacitação profissional para a educação em saúde, viabiliza o desenvolvimento dessas ações (JANINI, BESSLER; VARGAS, 2015).

O Centro de Saúde Etelvina Carneiro, localizado na região Norte de Belo Horizonte, foi escolhido para ser piloto na implantação do projeto e no desenvolvimento das atividades. A escolha foi baseada em uma proposta do Núcleo de Revitalização da Bacia do Izidora e a partir de uma demanda da gerência local, fundamentada na necessidade de projetos referentes à promoção da saúde, com foco na educação ambiental, priorizando áreas de risco sanitário e de vulnerabilidade social.

'Guardiões da Saúde' foi o termo destinado aos agentes da comunidade, profissionais do Centro de Saúde e integrantes do Projeto que atuaram no diagnóstico do território, por meio de coleta de dados e visitas técnicas à área de abrangência do Centro de Saúde Etelvina Carneiro, que se tornaram corresponsáveis pelo trabalho desenvolvido. Para a coleta desses dados, foi elaborado um instrumento para verificar a realidade do Centro de Saúde e da sua área de abrangência, em relação aos resíduos descartados, a fim de elaborar um diagnóstico da situação.

Identificaram-se, portanto, a ocupação desordenada da área, locais com saneamento básico inadequado, resíduos depositados indevidamente à beira de córregos e logradouros, entre outros problemas. Além disso, foi registrada a coleta de materiais recicláveis pelos catadores que recolhem latinhas, garrafas pet, papelão e outros materiais para subsistência e, em alguns casos, para complementar a renda. Foram apontadas, também, áreas com potencial para revitalização, como habitat de peixes, poluídas atualmente, e minas de água, dentro das edificações construídas irregularmente, assoreadas em seus cursos d'água.

Após esse diagnóstico, foram realizadas reuniões com as lideranças e parcerias do projeto, a fim de discutir a realidade e propostas de intervenção para as áreas afetadas. Com base nas informações coletadas, elaborou-se o Plano de Ação do Centro de Saúde contemplando os problemas encontrados, propostas de intervenções e busca pela conformidade da legislação vigente, colaborando para a resolução do gerenciamento de resíduos.

Entre as ações que estão vigentes e em desenvolvimento no Plano de ação, identificaram-se os catadores de materiais recicláveis e os tipos de materiais coletados, assim como a importância da geração de renda dessas pessoas.

Com base na Política Nacional de Resíduos Sólidos (BRASIL, 2010) que prevê, no art. $7^{\circ}$, como objetivo, a integração dos catadores de materiais reutilizáveis e recicláveis nas ações que envolvam a responsabilidade compartilhada pelo ciclo de vida dos produtos, buscou-se o reconhecimento e valorização dos catadores na comunidade em que atuam. Como parte do plano de ação do Centro de Saúde, espera-se promover a implantação da coleta seletiva solidária, além de vislumbrar a possibilidade de formação de associação e/ou cooperativa com os catadores da área, ou uma rede, a fim de proporcionar-lhes uma melhor qualidade de vida. Segundo Neves, Libel e Freitas (2016), os catadores atuam como agentes ambientais no recolhimento de resíduos da área, impactando, diretamente, nas condições de saúde da população.

O processo para formação da Associação ou Rede com Catadores Etelvina Carneiro, dar-se-á por meio de capacitações que abordarão a temática Coleta Seletiva, qualificando os catadores, técnicos e lideranças comunitárias para a segregação adequada dos resíduos, e pela Coleta Seletiva Solidária. Esta última trata-se do eixo de inclusão produtiva das pessoas em situação de extrema pobreza no Brasil, pertencente ao projeto Coleta Seletiva Solidária do Governo Federal que busca implantar uma cultura institucional para um novo modelo de gestão dos resíduos. Além disso, traçar rotas para os 
catadores de cada um dos agentes ambientais é imprescindível para o processo de formação da Associação ou Rede.

Na produção de Oliveira et al. (2015), destacou-se o trabalho de catadores de uma associação em Mossoró (RN). Essa instituição prima por princípios relacionados com a questão ecológica, com a educação popular e com a formação política de seus componentes. O resultado é o sentimento de pertencimento e compromisso no cuidado com o meio ambiente, em cada um dos catadores associados, manifestando-se por meio de práticas de educação ambiental, que podem ser vistas, como meio de geração de renda, por meio de ações de mobilização da comunidade.

Para a inclusão dos agentes ambientais na rota publicizada pela comunidade, na área de abrangência, a população precisa reconhecer os catadores como trabalhadores, além de entender os resíduos como um bem, que deve ser reutilizado e/ou reciclado. Para isso, há necessidade de ações de sensibilização e mobilização da população para realizar a coleta seletiva solidária (NEVES; LIBEL; FREITAS, 2016). Exercendo esse papel, a comunidade promove o fortalecimento do controle social que deve exercer sobre a gestão do sistema de saúde, sendo formalizado pelas Comissões Locais de Saúde (CLS) (SILVA; LIMA; TEIXEIRA, 2015). Os participantes desta comissão devem divulgar a ideologia da coleta seletiva solidária. A força da participação da comunidade com ações e proposições extrapola o controle social, mas, sim, representam engajamento para a ação e desafio para a proposição (DELDUQUE; SILVA; CARVALHO, 2014).

Pensando nisso, a abordagem com a população deve ter uma interpretação crítica da realidade, resgatando o sentido das experiências de vida dos sujeitos envolvidos, trabalhando o diálogo entre a epistemologia e os saberes populares (OLIVEIRA ET AL., 2015). Portanto, a representação comunitária em conjunto com os segmentos sociais demonstra a intersetorialidade (ORNELAS; TEIXEIRA, 2015), representados no Projeto por diferentes parceiros: educação, saúde, movimentos sociais, entre outros.

Experiências como essas tornam o setor saúde articulador e responsável pelo ideário e disseminação da intersetorialidade. Infere-se, portanto, que esse conceito está vinculado às redes sociais que são os fenômenos coletivos, os quais a dinâmica é resultado da conexão de muitos com objetivos de projetos comuns.

\section{Guardiões da Escola}

Segundo Valadão (2004), saúde escolar foi o termo genérico utilizado para denominar políticas e programas de saúde que são desenvolvidos nas escolas, sejam de natureza educativa, preventiva ou assistencial, que podem ser considerados integrantes do sistema de saúde. As ações de educação ambiental nas escolas tornaram-se fundamentais para atingir os objetivos do Projeto Izidora, implantando ações na comunidade escolar em conformidade com a legislação.

Diante desse quadro, ações de educação ambiental são extremamente importantes para a separação dos resíduos (RAIO, 2016). De acordo com Instituto de Pesquisa Econômica Aplicada (IPEA, 2012), no Brasil, os Resíduos Sólidos Urbanos (RSU) possuem uma disposição irregular, coleta informal e insuficiência do sistema de coleta pública que impedem que parte dos resíduos sólidos gerados sejam coletados e contabilizados. Além disso, a Política Nacional de Resíduos Sólidos (PNRS) (BRASIL, 2010) institui a responsabilidade, pelos resíduos gerados, compartilhada envolvendo cidadãos, empresas, escolas e gestores públicos das três esferas governamentais. No entanto, isso não se efetivou totalmente na prática. O Projeto Izidora, etapa 'Guardiões da Escola', busca atender à Lei $n^{\circ} 9.795$, de 27 de abril de 1999, que institui a Política Nacional de Educação Ambiental, que requer ações com foco ambiental a serem implantadas nas atividades docentes. 
Para a implantação das ações de educação ambiental do Projeto Izidora, foi selecionada uma escola municipal de Belo Horizonte, da região Norte da cidade, para ser piloto. Essas ações foram realizadas por etapas, conforme explicado a seguir.

Na primeira etapa, foi realizada sensibilização da comunidade escolar, na qual os alunos e profissionais da unidade foram convidados a integrar ao projeto de forma lúdica e interativa. Foram mobilizados a partir da apresentação de conceitos como resíduos sólidos, bacia hidrográfica e reciclagem, além da fala de um catador, que relatou sua experiência de vida e sua relação de trabalho e sobrevivência com os resíduos sólidos. Por fim, foi feito convite para que os alunos assumissem a tarefa de ser um 'Guardião da Escola', aquele que guarda o que gosta com amor.

$\mathrm{Na}$ segunda etapa, foram realizadas capacitações e dinâmicas com os 'Guardiões da Escola', para que fossem envolvidos no contexto e entendessem a escola inserida no ambiente da bacia hidrográfica e necessidade de revitalização e preservação dela.

Posteriormente, na terceira etapa, os alunos coletaram informações na escola para identificarem a realidade vivenciada em relação à poluição, causada principalmente pelo descarte inadequado de resíduos, consumo inadequado de água e energia elétrica.

Na quarta etapa, visita a pontos estratégicos da Bacia Hidrográfica do Izidora, com o objetivo de sensibilizar os alunos e os colocar na posição de corresponsáveis pela situação ambiental, de saúde coletiva e trabalhar para transformar essa realidade;

$\mathrm{Na}$ quinta etapa, foram elaborados planos de ação preliminares a serem desenvolvidos para solucionar os problemas apontados por meio da coleta de informações realizada pelos 'Guardiões da Escola'. Eles se tornaram responsáveis em transmitir e mobilizar os demais alunos para buscar a solução dos problemas encontrados.

Como a sexta etapa, foi realizado seminário para apresentação do Projeto ‘Guardiões da Escola' e divulgação dos resultados por uma apresentação cultural da escola. $\mathrm{Na}$ ocasião, foram distribuídos certificados e brindes para os Guardiões.

Em seguimento aos trabalhos, foram propostas ações contínuas para o cumprimento do objetivo principal, que é a Revitalização da Bacia do Ribeirão Izidora pela observação do plano de ação na escola piloto, no qual os alunos e profissionais da educação estavam empenhados e nas atividades para desenvolvimento do plano.

Na construção do plano de ação da escola piloto, foram identificados problemas como desperdício de energia elétrica, água potável e alimentos, além do descarte inadequado de resíduos pela escola e pelo lago no interior da edificação escolar, com água questionável para consumo humano e/ou recreação. Não se realizavam campanhas educativas com a finalidade de sensibilizar a comunidade escolar com relação ao não desperdício de alimentos, realizadas no refeitório. Para solucionar os problemas, foram feitos apontamentos dirigidos aos colegas, pelos 'Guardiões da Escola', sobre o desperdício de água potável e energia elétrica, ações de mobilização para a comunidade escolar por intermédio da divulgação do projeto, como implantação de coleta seletiva de alguns materiais, oficinas para customização de caixas para acondicionamento de material reciclável e visita ao Centro de Tratamento de Resíduos de Macaúbas, na cidade de Sabará, município responsável pelo tratamento adequado dos resíduos dos municipais de Belo Horizonte. Além disso, a escola conta com uma gestão que busca o desenvolvimento de ações de conscientização ambiental, como implementação de horta, a compostagem em tambor, geração de energia elétrica por meio de uma hidrelétrica abastecida pelas águas do lago no interior da escola.

Todas as ações realizadas somam-se ao objetivo de dar continuidade à abordagem ambiental por meio dos temas água, energia elétrica e resíduos trabalhados na etapa 
anterior do projeto. Foi realizada coleta de amostra da água do lago da escola e sua avaliação pela equipe da Vigilância Sanitária da Regional. Após análise, a água do lago foi liberada apenas para atividades em que as crianças e adolescentes não possam ter contato com ela, como lavação de pátio, de banheiros, aguar plantas, entre outras.

Na busca pela expansão do Projeto de Extensão, foi realizado encontro, na Regional Venda Nova, em abril de 2016, com técnicos do nível central da Secretaria Municipal de Saúde, representante da Rede Cataunidos e Projeto Manuelzão, além da Coordenação da Escola Integrada da Regional, representantes de todas as suas escolas e técnicos do nível central da Secretaria Municipal de Educação do município para divulgação do Projeto Izidora. Nessa ocasião, 15 escolas municipais preencheram uma declaração confirmando interesse na adesão e realização do Projeto Izidora - Etapa Gerenciamento de Resíduos.

É importante destacar que a Rede Cataunidos é um movimento criado para unir forças e promover aos catadores de materiais recicláveis melhores condições de vida e de trabalho. A rede promove um movimento cooperativista na busca pelo aumento da renda desses trabalhadores, além da preocupação com a preservação do meio ambiente. A Cataunidos está vinculada à Organização Não-Governamental (ONG) Instituto Nenuca de Desenvolvimento Sustentável (Insea), ambas articuladas por interesses em comum. Esses parceiros foram envolvidos para fortalecimento do Projeto Izidora.

Para dar início ao Projeto nas escolas que manifestaram interesse, o trabalho foi esquematizado por etapas. Na primeira etapa, realizou-se uma reunião inicial em que membros do Projeto da Secretaria Municipal de Saúde e bolsista de extensão da UFMG vinculado ao Curso de Gestão de Serviços de Saúde/UFMG se reúnem com os representantes responsáveis da Escola Integrada Local para apresentação do Projeto e de que forma ele acontecerá na escola. Nessa reunião, são apresentadas as propostas do projeto, como a coleta seletiva solidária, que dá início com o recolhimento de papéis, papelão, pilhas e, posteriormente, óleo de cozinha. A escola expõe demandas e/ ou necessidades espontâneas relacionadas com a educação ambiental ou revitalização de algum espaço, a serem trabalhadas em parceria com a equipe do Projeto. É definido sob a responsabilidade da escola, a seleção do grupo de alunos que serão os 'Guardiões da Escola', e que participarão de oficinas, visitas e serão os responsáveis pela divulgação da coleta do material para reciclagem.

Na segunda etapa, o Projeto é divulgado para os alunos. Os membros do Projeto da Secretaria Municipal de Saúde elaboram um folder que contém as principais informações a respeito das atividades que serão desenvolvidas e a escola reproduz, divulgando para toda a comunidade escolar. Essas ações foram realizadas em parceria com a equipe do Mobiliza SUS, que chamou a atenção dos alunos para o tema com uma fantasia de pernilongo-rajado, que é o vetor Aedes aegypti, transmissor da dengue.

A terceira etapa é uma oficina de customização de caixas que, após agendamento prévio com a escola, é realizada. Os alunos colam tecidos, jornais e/ou revistas em caixas recicladas de papel ofício, que são colocadas em locais estratégicos, definidos pelos responsáveis da escola, para armazenamento de papéis para reciclagem. Nessa etapa, é importante a participação e envolvimento dos funcionários, que realizam a limpeza da escola, visto que serão responsáveis pelo transporte, pesagem e acondicionamento do papel para reciclagem, pois a pesagem do papel é uma exigência da associação de catadores que recolherá o papel.

Em parceria com a Secretaria Municipal do Meio Ambiente (SMMA/BH) distribui-se galões recicláveis de água mineral nas escolas para armazenamento de pilhas. Esses galões são padronizados pela SMMA/BH e há um manual com instruções para sua utilização 
correta, que devem ser seguidas rigorosamente. Posteriormente, as pilhas recolhidas pela escola deverão ser encaminhadas para a Gerência de Manutenção, da respectiva regional, para destinação correta.

Na quarta etapa, são programadas visitas ao Aterro Sanitário de Sabará. O transporte dos alunos se dará pela própria escola ou pelo transporte do Projeto Manuelzão. Realizou-se a visita à Central de Tratamento de Resíduos de Macaúbas em Sabará, com explanação técnica do serviço prestado na linguagem das crianças, por profissional do próprio estabelecimento. Algumas considerações são fundamentais: em todas as etapas, há o acompanhamento de, pelo menos, um profissional do Projeto e um responsável por sua implantação na escola. Quando a escola apresenta alguma demanda espontânea são acionadas as parcerias para que o trabalho seja realizado da melhor maneira possível. A fase de coleta seletiva do óleo está em andamento, por meio de parceria com docentes da Escola de Engenharia de Produção da UFMG e o Insea, que possuem um projeto para recolhimento e destinação correta do óleo.

Foi identificado trabalho semelhante, relatado pela produção de Raio (2016), em que estudantes do $1^{\circ}$ ano no Ensino Médio, de uma escola técnica estadual paulista, foram sensibilizados por meio de uma pesquisa ação, isto é, mobilizados para o problema coletivo dos resíduos, envolvendo toda a comunidade escolar para a separação do resíduo escolar. Além de práticas tradicionais de ensino, como oficinas, palestras e capacitações, foi utilizada a metodologia virtual, na qual um jogo de computador foi criado pelos próprios alunos para a educação ambiental. O jogo foi vencedor de um prêmio, oferecido por uma empresa conhecida mundialmente. Mais importante que o prêmio, foram os resultados positivos obtidos a partir dessas práticas pedagógicas as quais estimularam, nos alunos envolvidos, a responsabilização pelo processo de gerenciamento de resíduos, fazendo-os propagar o conhecimento a respeito da segregação dos mesmos.

O setor Saúde está, cada vez mais, reconhecendo a necessidade de buscar parceiros para trabalhar o controle de riscos e garantir intervenções com promoção de espaços e comportamentos saudáveis. Nesse sentido, faz-se presente o reconhecimento de que é importante revisitar o conteúdo e as modalidades da cooperação técnica, visando à saúde individual, coletiva, ambiental e o desenvolvimento sustentável numa relação sinérgica (PERIAGO ET AL., 2007).

As ações intersetoriais enfrentam muitos obstáculos e carecem de comunicação entre os atores envolvidos. Essa comunicação pode ser obtida pela construção da real compreensão dos efeitos das mudanças ambientais e do despertar da cidadania, contribuindo para políticas nacionais e, mais tarde, para uma mobilização global, caracterizando assim uma comunicação ambiental (LIMA ET AL., 2015).

\section{Conclusões}

De acordo com o trabalho de Nascimento (2015), o principal objetivo do gerenciamento dos resíduos é proteger a saúde da população e promover a qualidade ambiental. Teixeira et al. (2014) ainda afirma que, as dificuldades de ampliação das ações conjuntas que extrapolam o setor saúde são justificadas pela fragilidade das equipes de serviços públicos e pela dificuldade encontrada em ações integradas com outros setores.

No entanto, conforme demonstrado até aqui, os objetivos do Projeto estão sendo alcançados por meio do trabalho intersetorial entre as diversas secretarias da gestão municipal, principalmente, as da Educação, Meio Ambiente e Saúde, além dos inúmeros parceiros como a UFMG e a Rede Cataunidos. Todos pelo intermédio da gestão e educação ambiental, que compõem um modelo de gestão integrada e compartilhada de resíduos sólidos, beneficiarão todo o território, com a melhoria da qualidade dos recursos hídricos, da bacia hidrográfica e 
do indivíduo, morador desse espaço geográfico a ser revitalizado.

Nesse sentido, Janini, Bessler e Vargas (2015) dizem que a promoção da saúde é viabilizada em centros de saúde pelas práticas de educação em saúde pelas práticas dos profissionais envolvidos, reafirmando vínculos com a comunidade.

Todas as atividades do Projeto Izidora são desenvolvidas com o objetivo de contribuir para a criação de uma consciência ambiental nos profissionais, alunos, comunidade escolar e comunidade local, para responsabilização continuada, participação e colaboração de todos em prol da revitalização da Bacia do Izidora.

O Projeto Izidora, assim como os projetos oriundos do seu extenso plano de ação, ainda é, como o dito popular, 'uma gota no oceano'; mas que, efetivamente, pratica-se a intersetorialidade, apesar de todos os obstáculos encontrados. As ações intersetoriais apresentam total potencial para transformação da realidade local, carecendo de informações para continuidade e sustentabilidade das ações (GARCIA ET AL., 2014).
Portanto, aos poucos, uma rede solidária é construída e a força gerada por cada ponta dessa rede é solta e forma-se uma linha horizontal, única, com os mesmos objetivos e sonho, que é a revitalização da Bacia do Córrego do Izidora, e as outras bacias envolvidas como a Bacia do Córrego do Onça, a Bacia do Rio das Velhas, a Bacia do Rio São Francisco. Até o momento, o Projeto tem abarcado 12, em um universo de 20 escolas municipais, entre as escolhidas como piloto e as que manifestaram interesse pela implantação do Projeto. Espera-se ampliar esse número para todas escolas municipais pretendidas, além de alcançar as áreas de abrangência das unidades básicas de saúde cobertas pela Bacia do Izidora. Dessa forma, as ações poderão ser transferidas para outras bacias hidrográficas do município e, assim, realizar a ação Gerenciamento de Resíduos Sólidos Urbanos, com a participação dos órgãos e secretarias da prefeitura, da sociedade civil organizada, além do setor empresarial e comunidade geral, colaborando para a construção de planos municipais de saúde e de políticas públicas participativas e aplicáveis. 


\section{Referências}

BRASIL. Lei no 9.795, de 27 de abril de 1999. Institui a Política Nacional de Educação Ambiental. Diário Oficial [da] União, Brasília, DF, 2010. Disponível em: <www.planalto.gov.br/ccivil_03/leis/L9795.htm>. Acesso em: 3 ago. 2016.

Lei $\mathrm{n}^{\circ} 12.305$, de 02 de agosto de 2010. Institui a Política Nacional de Resíduos Sólidos; altera a Lei no 9.605, de 12 de fevereiro de 1998; e dá outras providências. Diário Oficial [da] União, Brasília, DF, 2010. Disponível em: <http://www.planalto.gov.br/ ccivil_03/_ato2007-2010/2010/lei/112305.htm>. Acesso em: 3 ago. 2016.

Portal Brasil. Coleta Seletiva Solidária. 2011.

Disponível em: <http://www.brasil.gov.br/cidadania-e-justica/2011/10/coleta-seletiva-solidaria >. Acesso em: 3 ago. 2016.

BUSS, P. M.; PELLEGRINI FILHO, A. A saúde e seus determinantes sociais. Physis, Rio de Janeiro, v. 17, n. 1, p. 77-93, 2007. Disponível em: <http://www.scielo. br/pdf/physis/v17nl/v17nla06.pdf $>$. Acesso em: 3 ago. 2016.

CRUZ, D. O. A. et al. A transformação da realidade ambiental do território: mobilização social e empoderamento de profissionais e comunidade - Projeto Izidora. In: SIMPÓSIO BRASILEIRO DE SAÚDE E AMBIENTE, 2., 2014. Anais... Belo Horizonte: Abrasco, 2014. Disponível em: <http://www.sibsa. com.br/resources/anais/4/1404162565_ARQUIVO_ VersaoFinalpara2SimposioSaudeeMeioAmbiente2014. pdf $>$. Acesso em: 4 jun. 2016.

DELDUQUE, M. C.; SILVA, J. A. A.; CARVALHO, G. C. M. Participação da comunidade na saúde. Campinas: Saberes, 2014. Saúde em Debate, Rio de Janeiro, v. 39, n. 104, p. 288-289, mar. 2015. Disponível em: <http:// www.scielo.br/scielo.php?script=sci_arttext\&pid =S0103-11042015000100288>. Acesso em: 7 jun. 2016.

GARCIA, L. M. T. et al. Intersetorialidade na saúde no Brasil no início do século XXI: um retrato das experiências. Saúde em Debate, Rio de Janeiro, v. 38, n. 103, p.
966-980, dez. 2014. Disponível em: <http://www.scielo. br/pdf/sdeb/v38n103/0103-1104-sdeb-38-103-0966. pdf $>$. Acesso em: 3 jun. 2016.

GOUVEIA, N. Saúde e meio ambiente nas cidades: os desafios da saúde ambiental. Saúde e Sociedade, São Paulo, v. 8, n. 1, p. 49-61, fev. 1999. Disponível em: <http://www.scielo.br/scielo.php?pid=S0104$-12901999000100005 \&$ script=sci_abstract $>$. Acesso em 2 jun. 2016.

\section{INSTITUTO DE PESQUISA ECONÔMICA}

APLICADA (IPEA). Diagnóstico dos resíduos sólidos urbanos: relatório de pesquisa. Brasília, DF: IPEA, 2012 Disponível em: <http://www.ipea.gov.br/agencia/images/stories/PDFs/relatoriopesquisa/121009_relatorio_ residuos_solidos_urbanos.pdf>. Acesso em: 5 ago. 2016.

JANINI, J. P.; BESSLER, D.; VARGAS, A. B. Educação em saúde e promoção da saúde: impacto na qualidade de vida do idoso. Saúde em Debate, Rio de Janeiro, v. 39, n. 105, p. 480-490, jun. 2015. Disponível em: <http://www.scielo.br/pdf/sdeb/v39n105/0103-1104sdeb-39-105-00480.pdf>. Acesso em: 5 ago. 2016.

LIMA, M. D. V. et al. A comunicação ambiental e suas potencialidades no enfrentamento dos dilemas socioambientais. Desenvolvimento e Meio Ambiente, Curitiba, v. 34, p. 75-84, ago. 2015. Disponível em: $<$ http://revistas.ufpr.br/made/article/view/20353>. Acesso em: 5 ago. 2016.

NASCIMENTO, V. F. et al. Evolução e desafios no gerenciamento dos resíduos sólidos urbanos no Brasil. Revista Ambiente \&t Água, Taubaté, v. 10, n. 4, p. 889-902, dez. 2015. Disponível em: <http://www.scielo.br/scielo.php?pid=S1980$-993 X 2015000400889 \&$ script $=$ sci_abstract\&tlng=pt $>$. Acesso em: 5 ago. 2016.

NEVES, P. O.; LIBEL, C.; FREITAS, L. A coleta seletiva solidária integrando Universidade, escola e catadores de material reciclável em São Gabriel (RS). Revbea, São Paulo, v. 11, n. 2, p. 357-372, 2016. 
OLIVEIRA, L. G. S. et al. A contribuição dos catadores de lixo para a formação de uma Educação Ambiental no semi-árido nordestino do Brasil. Revbea, São Paulo, v. 10, n. 3, p. 97-110, 2015.

ORNELAS, A. L.; TEIXEIRA, M. G. C. Intersetorialidade ou diálogos setoriais? Reflexões a partir da experiência do Projeto Teias-Escola Manguinhos, Rio de Janeiro. Saúde em Debate, Rio de Janeiro, v. 39, n. 106, p. 659-670, set. 2015. Disponível em: <http://www.scielo.br/pdf/sdeb/v39n106/01031104-sdeb-39-106-00659.pdf>. Acesso em: 5 jun. 2016.

PERIAGO, M. R. et al. Saúde ambiental na América Latina e no Caribe: numa encruzilhada. Saúde \&t Sociedade, São Paulo, v. 16, n. 3, p. 14-19, dez. 2007. Disponível em: <http://www.revistas.usp.br/sausoc/ article/view/7541>. Acesso em: 5 jun. 2016.

RAIO, C. B. Gestão de resíduos e utilização de jogo eletrônico para a Educação Ambiental. Revbea, São Paulo, v. 11, n. 2, p. 192-202, 2016. Disponível em: <http:// www.sbecotur.org.br/revbea/index.php/revbea/article/viewFile/4583/3145>. Acesso em: 5 jun. 2016.

SANTOS, B. S. A universidade no século XXI: para uma reforma democrática e emancipatória da universidade. 2. ed. São Paulo: Cortez, 2005.

SILVA, K. L. et al. Intersetorialidade, determinantes socioambientais e promoção da saúde. Ciência \& Saúde Coletiva, Rio de Janeiro, v. 19, n. 11, p. 4361-4370, nov. 2014. Disponível em: <http://www.scielo.br/pdf/csc/ v19n11/1413-8123-csc-19-11-4361.pdf>. Acesso em: 5 jun. 2016.
SILVA, P. F. A.; BAPTISTA, T. W. F. A Política Nacional de Promoção da Saúde: texto e contexto de uma política. Saúde em Debate, Rio de Janeiro, v. 39, n. esp., p. 91-104, dez. 2015.

SILVA, V. M.; LIMA, S. M. L.; TEIXEIRA, M. Organizações Sociais e Fundações Estatais de Direito Privado no Sistema Único de Saúde: relação entre o público e o privado e mecanismos de controle social. Saúde em Debate, Rio de Janeiro, v. 39, n. esp., p. 145159, dez. 2015.

TEIXEIRA, M. B. et al. Avaliação das práticas de promoção da saúde: um olhar das equipes participantes do Programa Nacional de Melhoria do Acesso e da Qualidade da Atenção Básica. Saúde em Debate, Rio de Janeiro, v. 38, n. esp., p. 52-68, out. 2014. Disponível em: $<$ http://www.scielo.br/pdf/sdeb/v38nspe/0103-1104sdeb-38-spe-0052.pdf>. Acesso em: 5 jun. 2016.

VALADÃO, M. M. Saúde na Escola: um campo em busca de espaço na agenda intersetorial. 2004. 154 f. Tese (Doutorado) - Universidade de São Paulo, Faculdade de Saúde Pública, São Paulo, 2004.

VEIGA, R. S. et al. Implantação dos 5Ss e proposição de um SGQ para uma indústria de erva-mate. Revista ADMpg Gestão Estratégica, Ponta Grossa, v. 6, n. 1, p. 7178, 2013. Disponível em: <http://www.admpg.com.br/ revista2013_1/Artigos/14\%20Implantacao\%20dos\%20 5Ss\%20e\%20proposicao\%20de\%20um\%20SGQ.pdf>. Acesso em: 5 jun. 2016

Recebido para publicação em agosto de 2016 Versão final em dezembro de 2016

Conflito de interesses: inexistente

Suporte financeiro: bolsa Pró-Reitoria de Extensão - Proex/ UFMG 